\title{
Gender Differences in the Pharmacokinetics of Oral Drugs
}

\author{
Miriam del Carmen Carrasco-Portugal ${ }^{1}$, Francisco Javier Flores-Murrieta ${ }^{1,2}$ \\ ${ }^{1}$ Unidad de Investigación en Farmacología, Instituto Nacional de Enfermedades Respiratorias Ismael Cosío Villegas. México, D.F., \\ México; ${ }^{2}$ Sección de Estudios de Posgrado e Investigación, Escuela Superior de Medicina del Instituto Politécnico Nacional. México, \\ D.F., México. \\ Email: fjfloresmurrieta@yahoo.com.mx, fjfloresmurrieta@prodigy.net.mx
}

Received November $3^{\text {rd }}, 2010$; revised November $13^{\text {th }}, 2010$; accepted November $30^{\text {th }}, 2010$

\begin{abstract}
Establishment of rational dosage regimens requires the knowledge of pharmacokinetics and pharmacodynamics in the target population. It has been established that side effects produced by drugs are more frequent in women than in men. This may be due to two possibilities, one is that normalized dose received by women is higher than men and the other is that anatomical and physiological characteristics are a quite different. In this review, some aspects that may play a role in the generation of such differences are analyzed, including the impact on absorption, distribution, metabolism and excretion of drugs. Most of the changes can be explained by differences in volume of distribution and systemic clearance, however, presystemic clearance also seems to play a role in such dissimilarities. The final result, in general, is that women have higher plasma levels of drugs and usually these differences are reduced or abolished when data are normalized by the body weight, since both, volume of distribution and systemic clearance are influenced by it; however, there are some cases in which differences remain. Further research oriented to establish the role of each of the anatomical and physiological differences in the oral pharmacokinetics of drugs is warranted.
\end{abstract}

Keywords: Gender-Related Differences, Oral Pharmacokinetics, Sex Differences

\section{Introduction}

During the past decade, pharmacological research has greatly enhanced our understanding of several variables affecting the prescription of medication. One variable of increasingly recognized importance is gender. Up to $5 \%$ of all hospital admissions and up to 7000 deaths annually in the United States are the result of adverse drug reactions (ADRs) [1]. Identifying those factors that may predispose to ADRs are essential for risk management. Amongst the known risk factors for adverse drug reactions are increasing age, polypharmacy, liver and renal disease as well as being female. However, the reasons for this increased risk in female patients are not entirely clear but include gender related differences in pharmacokinetics, pharmacodynamics, immunological and hormonal factors as well as differences in the use of medications by women compared with men.

Female has been shown to be a risk factor for clinically relevant adverse drug reactions with a 1.5 to 1.7-fold greater risk of developing an adverse drug reaction compared to male patients [2]. The question is this distinction with the man is due to pharmacokinetics and/or pharmacodynamics differences or do females just receive more medication and higher doses than males?, or both actions play a role in these differences.

Initial drug concentrations after a bolus dose or loading dose and maximum peak concentrations $\left(C_{\max }\right)$ are dependent on the volume of distribution $(\mathrm{Vd})$. Average steady-state concentrations $\left(C^{\mathrm{Ss}}\right)$ are dependent on clearance $(\mathrm{Cl})$. For the majority of drugs, $\mathrm{Vd}$ and $\mathrm{Cl}$ are dependent on body weight; yet few drugs are dosed based on body weight. Generally, males weigh more than females. Therefore, based on differences in body weight alone, females often receive higher doses which results in higher concentration and drug exposure than males, irespective of other pharmacokinetic differences.

The first medication to be gender analyzed for pharmacokinetic differences was antipyrine in 1971 [3], this drug is eliminated entirely by hepatic metabolism, and the study showed that the half life of antipyrine was shorter in women. The next drug to be analyzed was acetaminophen, the clearance of this drug was faster in men than in women. In the past, women have been un- 
derrepresented in clinical trials, which have caused a relative lack of data to evaluate possible sex differences in drug efficacy and side effects. A main reason for this underrepresentation is the fear of potential teratogenicity. As a result, major studies involving the efficacy of drugs did not include women. The FDA includes more women in clinical trials since 2000 [4]. Since then, growing information about the influence of gender in the pharmacokinetics of drugs has been published.

It is well known that there are important physiological differences between women and men, that may produce differences in the pharmacokinetics of drugs, since all processes involved in the absorption, distribution, metabolism and excretion of drugs may be changed. In this review, an analysis about the influence of gender in these factors is carried out.

\section{Absorption}

Drug absorption is defined as the pass from the site of administration to the systemic circulation. Depending on the route of administration, the drug has to cross several barriers that may contribute to reduce the bioavailability. When the drug is administered intramuscularly, the possibility of a wrong administration is higher than in men. When the drugs are given orally, it has clearly established that gastric acid secretion, gastric emptying time, gastrointestinal blood flow, presystemic metabolism and transporters activity influence the absorption of drugs $[5,6]$. Although there is little information concerning changes due to gender in such factors, it has been established that changes in the bioavailability of several sustances may occur [7-10]. It has been reported that some hormones may modify gastric acid secretion, and therefore gastric $\mathrm{pH}$, and additionally, a slower gastric emptying time is present in females $[11,12]$. The conesquence of such changes is that a significative delay of the onset of effectiveness of enteric-coated dosage forms and drug solubility and dissolution rate may be modified [13]. However, contradictory results have been published since there is evidence indicating that no change in the pharmacokinetic parameters is observed in several studies. As it can be seen, it is not possible to predict a priori in which cases differences between women and men in the absorption of enteric coated formulations will be present, since several factors may contribute to the possible gender differences, and it is a quite difficult to establish if differences are due to these factors.

Other factor that may contribute to gender differences in the pharmacokinetics of drugs is the gastrointestinal blood flow [14]. It has been described that usually women have lower organ blood flow. The theoretical consequence of this diminished flow may be a slower rate and probably lower extent of drug absorption [15].
However, to our knowledge, there are no available data evaluating the influence of this reduced gastrointestinal blood flow described in women on the oral pharmacokinetics of drugs.

Additionally to the described aspects that may modify the oral absorption of drugs, presystemic metabolism may influence importantly the bioavailability of drugs. It has been described that the major oxidative enzymatic pathway involved is the intestinal CYP3A4. In this case, controversial results have been published. On one hand, it has been suggested that no significative sex-related difference in the activity and/or content of gastrointestinal CYP3A4 is observed [16,17], and therefore, no difference in the bioavailability of drugs due to this pathway is expected; but, on the other hand, in an elegant study carried out with verapamil, it has been demonstrated that presystemic metabolism was, at least partially responseble of the gender differences observed after administration of this drug orally [18]. These authors concluded that sex-differences in drug metabolism occur in both the gut and the liver and involve multiple metabolic pathways and an important thing is that pharmacokinetic differences will alter the pharmacodynamic responses. Studies oriented to evaluate both, presystemic and systemic metabolism surely will contribute to clarify the exact role of each of them in the gender-related differences in the pharmacokinetics of orally administered drugs.

A situation that has produced confusion about the role of presystemic metabolism is that most of drugs metabolized by CYP3A4 are also substrates of P-glycoprotein (Pgp), an efflux pump that reduce the bioavailability of drugs. In this case, also contradictory results have been reported. Results described by some authors indicate that activity is one-third to one-half lower in livers obtained from females compared with males [19], however in other in vitro study there were no difference in the expression of Pgp [20]. It is not easy to establish the role of Pgp in the gender-related differences in the oral pharmacokinetics of drugs for the above mentioned that CYP3A4 and Pgp share substrates. An interesting group of drugs that are substrates of Pgp and that are not metabolized by CYP3A4 are the fluoroquinolones [21,22]. Several studies have been carried out comparing the influence of gender on the oral pharmacokinetics of several drugs from this group, named ciprofloxacin, ofloxacin, levofloxacin, grapefloxacin and gatifloxacin. In all cases, higher plasma levels were reached in women when compared with men [23-27], but differences dissapear when data were normalized by the body weight of individuals. These results taken together seem to indicate that Pgp does not play an important role in the gender-related differences in the oral pharmacokinetics of drugs. However, 
it can not be completely ruled out as a genesis of sexrelated differences in the oral pharmacokinetics of drugs. Since several factors may contribute to gender differences in the absorption of drugs, the final result will depend on the characteristics of the compound and the extent of gender differences of each of the factors described. It is necessary further research oriented to establish which of the above mentioned factors have a major contribution to the gender-related differences in the oral pharmacokinetics of drugs.

\section{Distribution}

It is well known that gender differences in the composition of body are present. Some of the differences are body mass index, percent of body fat, plasma volume and organ blood flow [28,29]. It has been described that women have lower average body weight, higher body fat percentage, smaller average plasma volume and lower average organ blood flow than men [28-30]. As a result of these disparities, important distribution differences between genders are observed [30]. Other factor that may contribute to gender differences in distribution of drugs is the protein binding, since major protein groups responsible for binding drugs are influenced by concentration of sex hormones and therefore, changes in distribution may occur between genders and during the menstrual cycle $[31,32]$.

As a general rule, water-soluble compounds are more widely distributed in men than in women, since water content of men, normalized by the body weight, is about 15 to $20 \%$ higher than women. Some examples of this situation are fluconazole [33] and metronidazole [34], in which volume of distribution is bigger in men when compared with women, and such differences remain, although normalization by weight is carried out $[33,34]$. On the contrary, hydrophobic drugs are more widely distributed in women, due to higher fat percentage content [30]. However, most of the times, changes in volume of distribution of the drug are completely abolished when the parameter is normalized by the body weight. But the main concern is that usually, dosage regimens employed for most of the currently used drugs are not normalized by the body weight of individuals and this situation may explain, at least in part, the increased concentrations and therefore more frequency of side effects observed in women.

\section{Metabolism}

Probably, metabolism of drugs has received the main attention to explain gender differences in the pharmacokinetics of drugs. It has been described that activity of several enzymatic pathways is reduced in women when compared with men, whereas in other cases, other path- ways are increased in women. It is important to note that, enzymatic activity is not the only factor that influences the metabolism of drugs, and important contribution to this metabolism is given by the blood flow and protein binding of the drug. Hepatic metabolism is divided in two different kind of reactions, named phase I and phase II. Phase I reactions are oxidation, reduction and hydrolysis, whereas, phase II metabolic reactions include acetylation, sulfation, glucuronidation and methylation. Quantitatively, cytochrome P-450 (CYP) mediated oxidation is the major reaction and it has been described gender differences in several isozymes of this CYP. It has been reported that CYP3A4 is the major isozyme of this enzymatic pathway and is responsible of the metabolism of about $50 \%$ of the current used drugs [35], being for this reason the most important CYP. Controversial results have been published concerning the activity of this enzyme. On one hand, several authors have suggested (based on in vitro studies) that CYP3A4 activity is higher in women than in men, whereas CYP1A2 and CYP2D6 activity is higher in men, and no differences or contradictory results have been reported in other CYPs. Table 1 shows hepatic CYP and UDP-glucuronosyltransferase activity according to gender. However, although these differences have been reported in vitro, frequently they are not reflected in vivo, and therefore, contradictory results have been published. A summarized description of gender-related differences depending on the metabolic pathway, in which gender-related differences in the activity have been suggested, is given.

CYP1A2. This isozyme is responsible of the oxidative metabolism of several drugs including clozapine, olanzapine, theophylline and ondansetron. This CYP is the most induced isozyme by smoking [36]. It has been suggested that activity of this CYP is increased in men when compared with women. The result of this difference is

Table 1. Comparative activity of different enzymatic pathways between genders.

\begin{tabular}{cc}
\hline ENZYMATIC PATHWAY & ACTIVITY \\
\hline CYP1A2 & $\mathrm{M}>\mathrm{F}$ \\
CYP2C9 & $\mathrm{M}=\mathrm{F}$ \\
CYP2C19 & $\mathrm{M}>\mathrm{F}, \mathrm{M}=\mathrm{F}, \mathrm{F}>\mathrm{M}^{*}$ \\
CYP2D6 & $\mathrm{M}=\mathrm{F}$ \\
CYP2E1 & $\mathrm{M}>\mathrm{F}$ \\
CYP3A4 & $\mathrm{F}>\mathrm{M}, \mathrm{M}=\mathrm{F}^{*}$ \\
UGT & $\mathrm{M}>\mathrm{F}$ \\
\hline
\end{tabular}

$\mathrm{M}=$ males, $\mathrm{F}=$ females; ${ }^{*}$ contradictory results have been published. 
that higher levels of the drugs metabolized by this isozyme are observed in women. Examples of such disparities are observed with clozapine and olanzapine, in both cases plasma levels were higher in women and the potential of side effects is increased [37-39]. Similar results were observed when oral pharmacokinetics of ondansetron was compared between women and men, i.e. significative higher levels were reached in women [40]. Taken together, data reported indicate that CYP1A2 activity is higher in men compared with women, and therefore, it should be desirable to establish different dosage regimens based on the patient's gender.

CYP2C9. This is a polymorphic isozyme that is responsible of the metabolism of a wide variety of drugs, includeing phenytoin, several non-steroidal anti-inflammatory drugs (NSAIDs) (diclofenac, ibuprofen, piroxicam), and sulfonylureas (glyburide, glimepiride and glipizide). Although this is a polymorphic isozyme, evidence published seems to indicate that no gender-related differences are present, since no changes in oral pharmacokinetics of drugs metabolized by this pathway have been reported, including phenytoin, ibuprofen, tolbutamide, glyburide and ketoprofen [41,42]. However, a study carried out by Meyer et al. [43] described lower plasma levels of phenytoin when concentrations were normalized by the body weight, suggesting increased CYP2C9 activity in women. As it can be seen, contradictory results have been published, indicating that further studies oriented to clearly establish a possible gender-related difference in this enzymathic pathway should be carried out taken into account the body weight of individuals.

CYP2C19. This is also a polymorphic isozyme that is responsible of the metabolism of S-mephenytoin, diazepam and proton-pump inhibitors, including omeprazole, lansoprazole and pantoprazole [44]. So far, contradictory results have been reported concerning the gender-related differences in its activity. Some authors indicated that females have more activity than males, however, in other studies it has been reported that women have lower activity in comparison with men, and some authors indicate that no difference is observed [45]. There are several confusing factors that could explain these contradictory results, including the probe employed, ethnicity, and the intake of oral contraceptives [45]. Although most of the authors have reported that women have less activity in CYP2C19, further studies are required in order to clarify if there are gender-related differences in the activity of this important isozyme.

CYP2D6. Other polymorphic isozyme is CYP2D6 and is responsible of the oxidative metabolism of several drugs including betablockers, some analgesic, antiarrhytmics and antidepressants [46]. There is limited information concerning the possible gender-related differ- ences in the activity of this isozyme. On one hand, it has been reported that no changes due to gender are present [47], however, when oral pharmacokinetics of metoprolol (a drug that is metabolized by CYP2D6) was compared between women and men, higher levels of metoprolol were found in women, indicating a higher metabolism in men, however, in other study no changes were observed [48-50]. These contradictory results do not allow us rule out gender-related differences in the oral pharmacokinetics of drugs metabolized by CYP2D6. Although most of the evidence indicate a lack of gender-related differences in the CYP2D6 activity, further studies are necessary in order to clarify this doubt.

CYP2E1. This isozyme has producing a growing interest due to its polymorphism and the consequences of such variability. This pathway is responsible of the metabolism of ethanol, chlorzoxazone and some anesthetics such as halothane, isoflurane, diethylether and methoxyflurance [51-52]. The activity of this isozyme has been measured as the ratio of 6-hydroxychlorzoxazone/chlorzoxazone, and it has been described that women have about $30 \%$ lower activity than men [45]. The importance of such difference in activity of CYP2E1 in the sex-related differences in the pharmacokinetics of drugs remains to be elucidated. This may be due to the low number of substrates of this isozyme and the route of administration usually employed in most of these compounds.

CYP3A4. This isozyme is the most abundant CYP in the human liver and intestinal tract. Additionally, it is responsible of the oxidative metabolism of at least $50 \%$ of the current used drugs [35]. That is why, it has been widely studied. It has been described that activity of this isozyme is 20 to $50 \%$ higher in women when compared with men [45]. However, other authors have not found any difference between genders when oral pharmacokinetics of drugs has been compared [47,53,54]. Additionally to these studies, it has been evaluated the differences in the urinary excretion of 6-betahydroxycortisol/cortisol (a marker of hepatic CYP3A4) in Asian and Caucasian women [55]. In this study, differences between populations were found and this may be a confusing factor that may play a role in the evaluation of possible gender differences in the oral pharmacokinetics of drugs. An additional factor is the wide variability found in the activity of this enzymatic pathway, as well as, the possible role of Pgp in the generation of the differences. In this way, it has been suggested that no differences are observed in CYP3A4 activity between genders and that the differences are completely explained by different activity of hepatic Pgp in women [56]. Due to these controversial results, further studies oriented to establish the role of CYP3A4 and Pgp in these gender-related differences are necessary. This is a big challenge since these systems 
share substrates and the net result obtained in vivo is a mixture of the participation of both systems.

UDP-glucuronosyl transferases (UGT). This is a group of isozymes that is formed by two families. It has been suggested that activity of UGT activity may be reduced in females compared with males, based on elimination of temazepam, oxazepam, acetaminophen, clofibric acid, diflunisal, labetalol and mycophenolic acid [57]. This information is limited to conclude which of the families of UGP may be involved in such differences and further studies are required to establish the role of these dissimilarities in therapeutics.

\section{Excretion}

Excretion of drugs can be carried out by several pathways, however, renal excretion is one of the most important routes of drug excretion. Glomerular filtration rate (GFR) is lower in women than in men, moreover, after normalizing GFR by the body size, a $10 \%$ difference remains [58] and therefore, renal clearance may be diminished for a wide variety of drugs. Concerning other mechanisms involved in the renal clearance, it has been reported sex-related differences in the tubular secretion and reabsorption. It has been established that clearance of taurocholate is increased in female rats when compared with male rats, indicating an increased reabsorption process in females $[59,60]$. In addition, it has been also reported increased urinary excretion of organic anions in female rats in comparison with male rats [60-62] indicating that renal clearance of organic anions may be increased in females. However, in general renal clearance observed in women is lower than the values obtained in men. Probably this may be due to the increased GFR observed in men that seems to have the major role in the renal clearance of drugs.

Impact of gender-related differences in the oral pharmacokinetics of drugs

As mentioned above, there are an important number of factors that may contribute to the gender differences in the pharmacokinetics of drugs. The final result will be in function of the different mechanisms involved in the absorption, distribution, metabolism and excretion of the drug. As stated above, gender-related differences seem to be due to several factors. On one hand, dosage regimens usually are given without normalizing by the body weight, having as a consequence higher doses in women in comparison with men. On the other hand, there are several physiological conditions that are different between genders and that are reflected in disimilarities in the oral pharmacokinetics of drugs. Probably the two parameters that are more affected by this situation are volume of distribution and systemic clearance. It has been reported that major molecular differences between mammalian sexes are involved in drug metabolism and renal function [63]. Both depend on the individual body weight. However, there are other physiological characteristics that may influence them. Additionally to body weight of the individual, volume of distribution is the result of protein and tissue binding, body fat and plasma volume. At least binding and body fat may be dissimilar in women in comparison with men, resulting in different distribution profile [28-31]. These characteristics leads to gender-related differences in the pharmacokinetics and therefore to a different effect profile. In addition to the distribution differences, systemic clearance plays a major role in the pharmacokinetic differences between genders $[11,30,45]$. As known, systemic clearance is the sum of all organs clearance, being the most important hepatic and renal clearances. In addition, the role of presystemic clearance (due to Pgp or gut metabolism) should not be ruled out, since in some cases it is very important in the reduction of bioavailability and may be responsible of gender-related differences in the oral pharmacokinetics of drugs.

In the last years, a growing interest in the gender differences in the pharmacokinetics has resulted in studies designed to elucidate the possible differences. However, contradictory results have been obtained. There are several reasons that may explain these contradictions. Usually, studies are carried out in small groups of subjects, normalized administered dose employed is different, it is not controlled the use of oral contraceptives and some other factors that may have influence in the results. Although these limitations, in the cases in which gender-related differences were observed, it has been described that plasma levels reached in women are higher than those obtained in men. It is interesting to note that from 300 new drug applications to FDA from 1995 to 2000 , in 163 a gender analysis was included, 11 drugs showed a difference higher than $40 \%$ [45].

In order to contribute to the establishment of gender differences in the pharmacokinetics, our group evaluated the oral pharmacokinetics of three drugs, pantoprazole, levofloxacin and losartan in women and men. In the first study, oral pharmacokinetics of enteric coated formulation of pantoprazole was evaluated in 52 healthy volunteers (26 women and 26 men). It was observed that higher plasma levels were reached in women, but such differences dissapeared when data were normalized by the administered dose (Figure 1); this was reflected in differences in several pharmacokinetic parameters, Cmax, AUC and $\mathrm{CL} / \mathrm{F}$. When values were normalized by the body weight of individuals, it can be seen that volume of distribution is slightly lower in women (Table 2). These results seem to indicate that volume of distribution is reduced in about $20 \%$ in women than in men, that may 


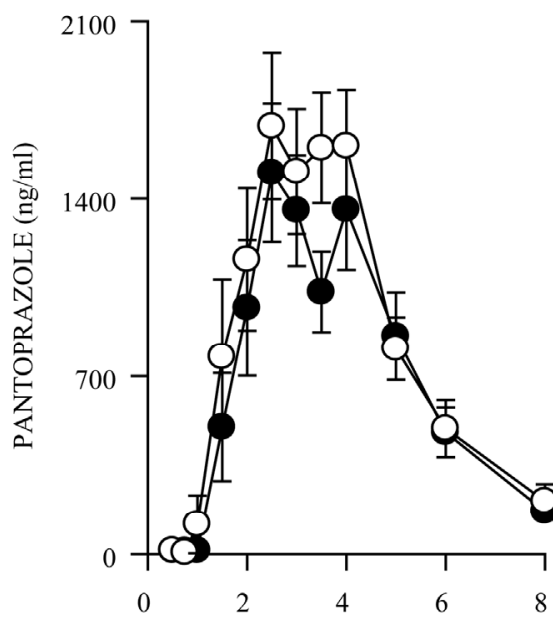

(a)

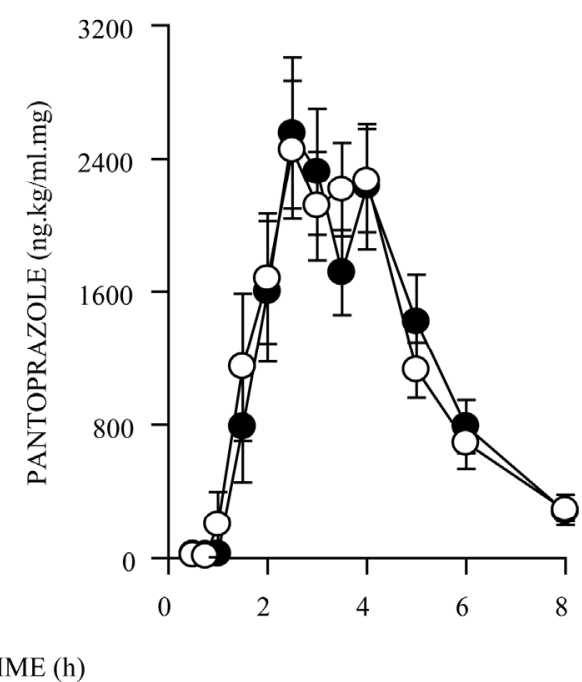

(b)

Figure 1. Plasma level-time curves in women (open circles) and men (dark circles) after administration of a single oral $40 \mathrm{mg}$ pantoprazole dose. A) Raw data and B) normalized by the dose data (in $\mathrm{mg} / \mathrm{kg}$ ). Data are expressed as mean \pm s.e.m.

Table 2. Demographic data and pharmacokinetic parameters of pantoprazole obtained in women and men after administration of a single $40 \mathrm{mg}$ oral dose. Data are expressed as mean \pm s.e.m. * $\mathrm{p} \leq \mathbf{0 . 0 5}$.

\begin{tabular}{|c|c|c|}
\hline Parameter & Men & Women \\
\hline Age (years) & $21.31 \pm 0.47$ & $24.38 \pm 1.10^{*}$ \\
\hline Height $(\mathrm{cm})$ & $167.35 \pm 1.19$ & $156.92 \pm 0.88^{*}$ \\
\hline Weight (kg) & $67.39 \pm 1.40$ & $57.87 \pm 2.42 *$ \\
\hline $\mathrm{C}_{\max }(\mathrm{ng} / \mathrm{ml})$ & $3131.15 \pm 152.54$ & $3248.70 \pm 228.40$ \\
\hline $\mathrm{NC}_{\max }$ (ng.kg/ml.mg) & $5207.21 \pm 211.59$ & $4615.56 \pm 319.98$ \\
\hline $\mathrm{t}_{\max }(\mathrm{h})$ & $2.88 \pm 0.20$ & $2.77 \pm 0.21$ \\
\hline $\mathrm{AUC}_{8 \mathrm{~h}}(\mathrm{ng} \cdot \mathrm{h} / \mathrm{ml})$ & $5455.60 \pm 346.21$ & $7190.20 \pm 724.26^{*}$ \\
\hline $\mathrm{NAUC}_{8 \mathrm{~h}}$ (ng.h.kg/ml.mg) & $9064.77 \pm 512.94$ & $10142.28 \pm 977.31$ \\
\hline $\mathrm{AUC}_{\infty}(\mathrm{ng} . \mathrm{h} / \mathrm{ml})$ & $5787.62 \pm 401.24$ & $8015.38 \pm 1056.81^{*}$ \\
\hline $\mathrm{NAUC}_{\infty}$ (ng.h.kg/ml.mg) & $9612.61 \pm 607.37$ & $11332.01 \pm 1432.14$ \\
\hline$t_{1 / 2}(h)$ & $1.26 \pm 0.05$ & $1.31 \pm 0.13$ \\
\hline $\mathrm{Vd} / \mathrm{F}(\mathrm{l})$ & $13.68 \pm 0.91$ & $10.69 \pm 0.72 *$ \\
\hline $\mathrm{NVd} / \mathrm{F}(1 / \mathrm{kg})$ & $0.202 \pm 0.012$ & $0.185 \pm 0.011$ \\
\hline $\mathrm{CL} / \mathrm{F}(\mathrm{l} / \mathrm{h})$ & $7.71 \pm 0.52$ & $6.43 \pm 0.55$ \\
\hline NCL/F (1/h.kg) & $0.114 \pm 0.007$ & $0.112 \pm 0.010$ \\
\hline
\end{tabular}

$\mathrm{N}$ indicates the normalized values taking into account the dose normalized by the body weight.

be due to differences in the body water between women and men. In the second study, the oral pharmacokinetics of levofloxacin was evaluated in 28 women and 27 men. Figure 2 shows the plasma levels time curve after administration of the drug before and after normalization of the dose by the body weight. It can be seen that plasma levels reached are about $20 \%$ higher in women, but the difference completely dissapeared when data were normalized by the individuals weight. Pharmacokinetic parameters (raw and normalized) are given in Table 3. It is clearly shown that the differences observed with this drug are exclusively due to the given dose (higher normalized dose is given in women).

In the third study, oral pharmacokinetics of losartan 

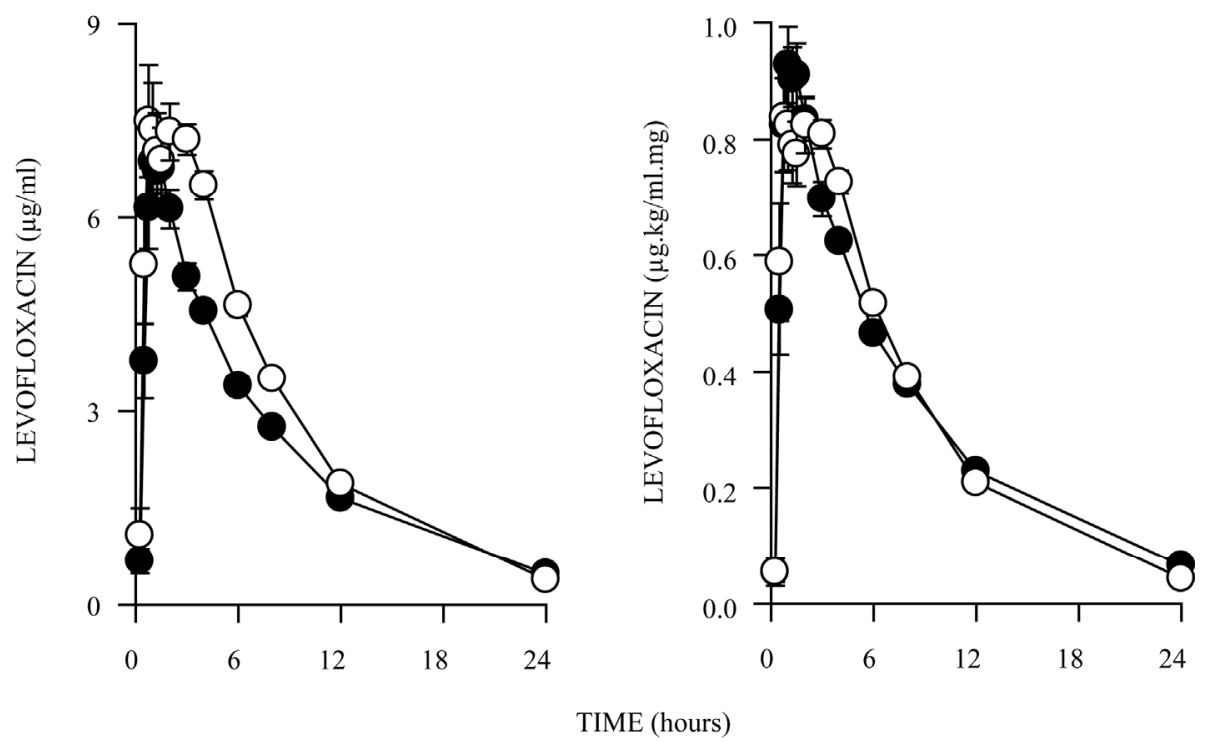

Figure 2. Plasma level-time curves in women (open circles) and men (dark circles) after administration of a single oral $500 \mathrm{mg}$ levofloxacin dose. (Left) Raw data and (right) normalized by the dose data (in $\mathrm{mg} / \mathrm{kg}$ ). Data are expressed as mean \pm s.e.m.

Table 3. Demographic data and pharmacokinetic parameters of levofloxacin obtained in women and men after administration of a single $500 \mathrm{mg}$ oral dose. Data are expressed as mean \pm s.e.m. ${ }^{*}$ p $<0.05,{ }^{* *}$ p $<0.0005,{ }^{\#}$ p $<0.0001$.

\begin{tabular}{lcc}
\hline \multicolumn{1}{c}{ Parameter } & Men & Women \\
\hline Age (years) & $22.52 \pm 1.00$ & $25.82 \pm 1.35$ \\
Height $(\mathrm{cm})$ & $168.83 \pm 1.47$ & $157.57 \pm 1.09^{*}$ \\
Weight $(\mathrm{kg})$ & $69.11 \pm 1.74$ & $56.50 \pm 1.25^{*}$ \\
$\mathrm{C}_{\max }(\mu \mathrm{g} / \mathrm{ml})$ & $8.45 \pm 0.45$ & $10.28 \pm 0.51^{* *}$ \\
$\mathrm{NC}_{\max }(\mu \mathrm{g} . \mathrm{kg} / \mathrm{ml} . \mathrm{mg})$ & $1.14 \pm 0.05$ & $1.15 \pm 0.05$ \\
$\mathrm{t}_{\max }(\mathrm{h})$ & $1.47 \pm 0.18$ & $1.89 \pm 0.23$ \\
$\mathrm{AUC} \infty(\mu \mathrm{g} \cdot \mathrm{h} / \mathrm{ml})$ & $60.75 \pm 1.52$ & $72.10 \pm 2.38^{\#}$ \\
$\mathrm{NAUC} \infty(\mu \mathrm{g} \cdot \mathrm{h} . \mathrm{kg} / \mathrm{ml} . \mathrm{mg})$ & $8.31 \pm 0.19$ & $8.05 \pm 0.20$ \\
$\mathrm{t}_{1 / 2}(\mathrm{~h})$ & $6.37 \pm 0.12$ & $5.00 \pm 0.08^{* *}$ \\
$\mathrm{Vd} / \mathrm{F}(\mathrm{l})$ & $76.75 \pm 2.36$ & $51.24 \pm 1.56^{\#}$ \\
$\mathrm{NVd} / \mathrm{F}(\mathrm{l} / \mathrm{kg})$ & $1.116 \pm 0.029$ & $0.907 \pm 0.020$ \\
$\mathrm{CL} / \mathrm{F}(\mathrm{l} / \mathrm{h})$ & $8.37 \pm 0.21$ & $7.14 \pm 0.23^{* *}$ \\
$\mathrm{NCL} / \mathrm{F}(\mathrm{l} / \mathrm{h} . \mathrm{kg})$ & $0.122 \pm 0.003$ & $0.126 \pm 0.003$ \\
\hline
\end{tabular}

$\mathrm{N}$ indicates the normalized values taking into account the dose normalized by the body weight.

was evaluated in 26 women and 26 men. Figure 3 shows the plasma levels time curve after administration of 50 $\mathrm{mg}$ of the drug. It can be seen that plasma levels reached are higher in women than in men. When pharmacokinetic parameters were normalized by the body weight, an increased clearance was observed in women (Table 4).

Results obtained in these three studies and two other studies previously reported by our group with flucona- zole [33] and clindamycin [54] indicate that plasma levels reached were higher in women, although different metabolic pathways or transporters were involved (CYP3A4, CYP2C9, CYP2C19, Pgp). One drug that allows to establish the differences in the distribution of the drug between men and women is fluconazole [33]. As fluconazole is widely distributed in total body water (TBW), and, since men have more content of TBW, volume of distribution 


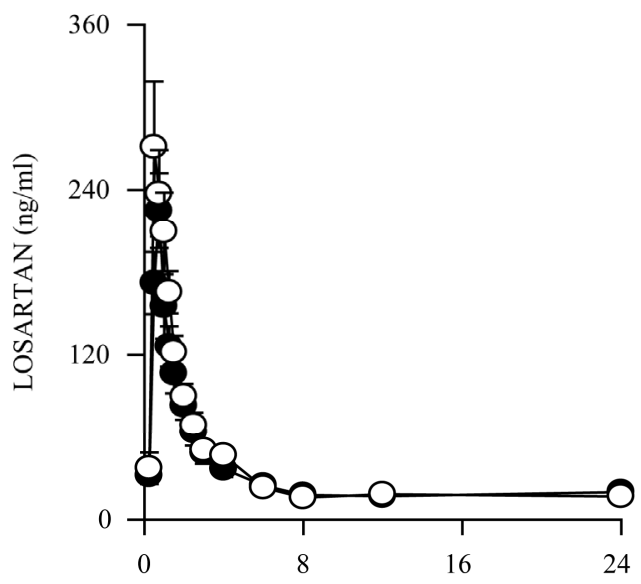

(a)

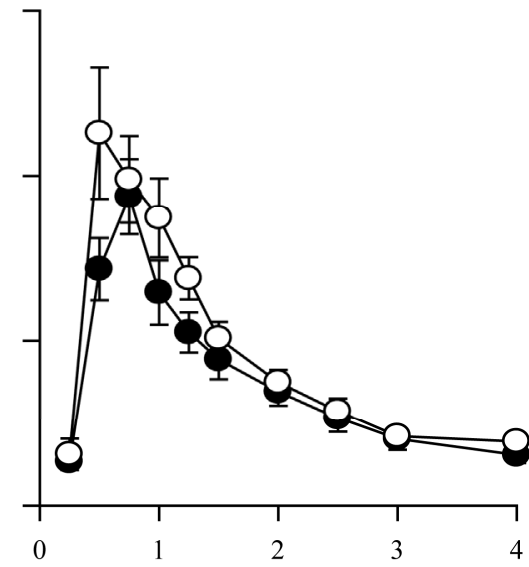

(b)

Figure 3. Plasma level-time curves in women (open circles) and men (dark circles) after administration of a single oral $50 \mathrm{mg}$ losartan dose. A) Data during the whole sample time period and B) data in the first 4 hours after losartan administration. Data are expressed as mean \pm s.e.m.

Table 4. Demographic data and pharmacokinetic parameters of losartan obtained in women and men after administration of a single $50 \mathrm{mg}$ oral dose. Data are expressed as mean \pm s.e.m. ${ }^{*} \mathrm{p}<0.01,{ }^{* * *} \mathrm{p}<0.002,{ }^{* * * *} \mathrm{p}<0.001$.

\begin{tabular}{|c|c|c|}
\hline Parameter & Men & Women \\
\hline Age (years) & $23.65 \pm 0.71$ & $25.46 \pm 1.14^{*}$ \\
\hline Height (cm) & $172.46 \pm 1.57$ & $156.81 \pm 1.31^{*}$ \\
\hline Weight (kg) & $70.31 \pm 2.11$ & $58.37 \pm 2.13^{* * *}$ \\
\hline $\mathrm{C}_{\max }(\mathrm{ng} / \mathrm{ml})$ & $249.42 \pm 24.67$ & $373.14 *$ \\
\hline $\mathrm{NC}_{\max }$ (ng.kg/ml.mg) & $343.19 \pm 34.43$ & $441.50 \pm 56.55$ \\
\hline$t_{\max }(h)$ & $0.91 \pm 0.09$ & $1.02 \pm 0.16$ \\
\hline $\mathrm{AUC}_{24 \mathrm{~h}}(\mathrm{ng} \cdot \mathrm{h} / \mathrm{ml})$ & $445.92 \pm 38.51$ & $673.85 \pm 50.04^{* * *}$ \\
\hline AUC $\infty$ (ng.h/ml) & $522.33 \pm 43.74$ & $789.08 \pm 64.74^{* *}$ \\
\hline NAUC $\infty$ (ng.h.kg/ml.mg) & $717.02 \pm 59.36$ & $923.32 \pm 99.05$ \\
\hline$t_{1 / 2}(h)$ & $3.15 \pm 0.53$ & $3.89 \pm 1.02$ \\
\hline $\mathrm{Vd} / \mathrm{F}(1)$ & $441.30 \pm 61.60$ & $316.80 \pm 44.30$ \\
\hline $\mathrm{NVd} / \mathrm{F}(1 / \mathrm{kg})$ & $6.2765 \pm 0.8761$ & $5.4274 \pm 0.7590$ \\
\hline $\mathrm{CL} / \mathrm{F}(\mathrm{l} / \mathrm{h})$ & $0.91 \pm 0.09$ & $1.02 \pm 0.16$ \\
\hline NCL/F (1/h.kg) & $0.0129 \pm 0.0013$ & $0.0175 \pm 0.0027^{* * *}$ \\
\hline
\end{tabular}

$\mathrm{N}$ indicates the normalized values taking into account the dose normalized by the body weight.

was higher in men and therefore, plasma concentrations were lower than in women. On the other hand, to our knowledge the only case in which plasma levels reached, normalized by the dose, are lower in women is with metronidazole [34], in which increased clearance and lower half-life was obtained.

As it can be seen, it is not possible to anticipate gen- der-related differences in the oral pharmacokinetics of drugs, and therefore, it is important to evaluate case by case in order to establish the adequate dosage regimen according to body weight and gender, although in most of the cases higher levels are reached in women than in men and such difference is mainly due to the administration of higher normalized doses in women. 


\section{Conclusions}

There is enough evidence that indicate that gender related differences in the pharmacokinetics of drugs exist. In general, higher plasma levels are reached in women than in men and such differences are mainly due to differences in the volume of distribution, due to different content of body water, and in clearance due to renal flow and metabolic activity. However, it seems that an important contribution for observing higher levels in women is that usually doses employed in women are higher than in men when they are normalized by the body weight.

\section{REFERENCES}

[1] L. T. Khon, "Organizing and Managing Care in a Changing Health System," Health Service Research, Vol. 35, No. 1, 2000, pp. 37-52.

[2] J. C. Kando, K. A. Yonkers and J. O. Cole, "Gender as a Risk Factor for Adverse Events to Medications," Drugs, Vol. 50, No. 1, 1995, pp. 1-6. doi:10.2165/00003495-199550010-00001

[3] M. J. Berg, "Drugs, Vitamins, and Gender," Journal of Gender-Specific Medicine, Vol. 2, 1999, pp. 18-20.

[4] GAO/HEHS-00-96. May 2000.

[5] M. N. Martinez and G. L. Amidon, "A Mechanistic Approach to Understanding the Factors Affecting Drug Absorption: A Review of Fundamentals," Journal of Clinical Pharmacology, Vol. 42, No. 6, 2002, pp. 620-643. doi:10.1177/00970002042006005

[6] W. Aichhorn, M. Gasser, E. M. Weiss, et al., "Gender Differences in Pharmacokinetics and Side Effects of Second Generation Antipsychotic Drugs," Current Neuropharmacology, Vol. 3, No. 1, 2005, pp. 73-85. doi:10.2174/1570159052773440

[7] C. J. Timmer, J. M. Sitsen and L. P. Delbressine, "Clinical Pharmacokinetics of Mirtazapine," Clinical Pharmacokinetics, Vol. 38, No. 6, 2000, pp. 461-474. doi:10.2165/00003088-200038060-00001

[8] S. L. Miaskiewicz, C. A. Shively and E. S. Vesell, "Sex Differences in Absorption Kinetics of Sodium Salicylate," Clinical Pharmacology and Therapeutics, Vol. 31, No. 1, 1982, pp. 30-37. doi:10.1038/clpt.1982.5

[9] T. Walle, R. P. Byington, C. D. Furberg, et al., "Biologic Determinants of Propranolol Disposition: Results from 1308 Patients in the Beta-Blocker Heart Attack Trial," Clinical Pharmacology and Therapeutics, Vol. 38, No. 5, 1985, pp. 509-518. doi:10.1038/clpt.1985.216

[10] D. Abernethy, M. Divoll and D. Greenblatt, "Obesity, Sex, and Acetaminophen Disposition," Clinical Pharmacology and Therapeutics, Vol. 31, 1982, pp. 783-790. doi:10.1038/clpt.1982.111

[11] M. Gandhi, F. Aweeka, R. M. Greenblatt, et al., "Sex Differences in Pharmacokinetics and Pharmacodynamics," Annual Review of Pharmacology and Toxicology, Vol. 44, 2004, pp. 499-523. doi:10.1146/annurev.pharmtox.44.101802.121453

[12] T. Coskun, A. Sevinc, I. Tevetoglu, et al., "Delayed Gastric Emptying in Conscious Male Rats Following Chronic Estrogen and Progesterone Treatment," Research in Experimental Methods, Vol. 195, 1995, pp. 49-54.

[13] M. D. Donovan, "Sex and Racial Differences in Pharmacological Response: Effect of Route of Administration and Drug Delivery System on Pharmacokinetics," Journal of Womens Health, Vol. 14, No. 1, 2005, pp. 30-37. doi:10.1089/jwh.2005.14.30

[14] C. V. Fletcher, E. P. Acosta and J. M. Strykowski, "Gender Differences in Human Pharmacokinetics and Pharmacodynamics," Journal of Adolescent Health, Vol. 15, No. 8, 1994, pp. 619-629. doi:10.1016/S1054-139X(94)90628-9

[15] J. B. Schwartz, "The Influence of Sex on Pharmacokinetics," Clinical Pharmacokinetics, Vol. 42, No. 2, 2003, pp. 107-121. doi:10.2165/00003088-200342020-00001

[16] T. N. Johnson, M. S. Tanner and G. T. Tucker, "A Comparison of the Ontogeny of Enterocytic and Hepatic Cytochromes P450 3A in the Rat," Biochemical Pharmacology, Vol. 60, No. 11, 2000, pp. 1601-1610. doi:10.1016/S0006-2952(00)00485-8

[17] J. C. Kolars, P. Schmiedlin-Ren, W. O. Dobbins, et al., "Heterogeneity of Cytochrome P-450 IIIA Expression in Rat Gut Epithelia," Gastroenterology, Vol. 100, 1992, pp. 1186-1198.

[18] M. E. Krecic-Shepard, C. R. Barnas, J. Slimko, et al., "Gender-Specific Effects on Verapamil Pharmacokinetics and Pharmacodynamics in Humans," Journal of Clinical Pharmacology, Vol. 40, No. 3, 2000, pp. 219-230. doi: $10.1177 / 00912700022008883$

[19] E. G. Schuetz, K. N. Furuya and J. D. Schuetz, "Interindividual Variation in Expression of P-Glycoprotein in Normal Human Liver and Secondary Hepatic Neoplasms," Journal of Pharmacology and Experimental Therapeutics, Vol. 275, No. 2, 1995, pp. 1011-1018.

[20] R. Wolbold, K. Klein, O. Burk, et al., "Sex is a Major Determinant of CYP3A4 Expression in Human Liver," Hepatology, Vol. 38, No. 4, 2003, pp. 978-988.

[21] L. Rabbaa, S. Dautrey, N. Colas-Linhart, et al., "Intestinal Elimination of Ofloxacin Enantiomers in the Rat: Evidence of a Carrier-Mediated Process," Antimicrobial Agents and Chemotherapy, Vol. 40, No. 9, 1996, pp. 2126-2130.

[22] A. Aminimanizani, P. Beringer and R. Jelliffe, "Comparative Pharmacokinetics and Pharmacodynamics of the Newer Fluoroquinolone Antibacterials," Clinical Pharmacokinetics, Vol. 40, No. 3, 2001, pp. 169-187. doi:10.2165/00003088-200140030-00003

[23] B. R. Overholser, M. B. Kays, A. Forrest, et al., "SexRelated Differences in the Pharmacokinetics of Oral Ciprofloxacin," Journal of Clinical Pharmacology, Vol. 44, No. 9, 2004, pp. 1012-1022. doi: $10.1177 / 0091270004266843$

[24] K. M. Sowinski, S. R. Abel, W. R. Clark, et al., "Effect of 
Gender on the Pharmacokinetics of Ofloxacin," Pharmacotherapy, Vol. 19, No. 4, 1999, pp. 442-446. doi:10.1592/phco.19.6.442.31044

[25] S. C. Chien, A. T. Chow, J. Natarajan, et al., "Absence of Age and Gender Effects on the Pharmacokinetics of a Single 500-Milligram Oral Dose of Levofloxacin in Healthy Subjects," Antimicrobial Agents and Chemotherapy, Vol. 41, No. 7, 1997, pp. 1562-1565.

[26] C. Efthymiopoulos, S. L. Bramer and A. Maroli, "Effect of Age and Gender on the Pharmacokinetics of Grepafloxacin," Clinical Pharmacokinetics, Vol. 33, No. 1, 1997, pp. 9-17. doi:10.2165/00003088-199700331-00004

[27] X. Zhang, B. R. Overholser, M. B. Kays, et al., "Gatifloxacin Pharmacokinetics in Healthy Men and Women," Journal of Clinical Pharmacology, Vol. 46, No. 10, 2006, pp. 1154-1162. doi:10.1177/0091270006291840

[28] I. Beierle, B. Meibohm and H. Derendorf, "Gender Differences in Pharmacokinetics and Pharmacodynamics," International Journal of Clinical Pharmacology and Therapeutics, Vol. 37, No. 11, 1999, pp. 529-547.

[29] R. Z. Harris, L. Z. Benet and J. B. Schwartz, "Gender Effects in Pharmacokinetics and Pharmacodynamics," Drugs, Vol. 50, No. 2, 1995, pp. 222-239. doi:10.2165/00003495-199550020-00003

[30] H. Pleym, O. Spigset, E. D. Kharasch, et al., "Gender Differences in Drug Effects: Implications for Anesthesiologists," Acta Anesthesiologica Scandinavia, Vol. 47, No. 3, 2003, pp. 241-259. doi:10.1034/j.1399-6576.2003.00036.x

[31] M. Succari, M. J. Foglietti and F. Percheron, "Microheterogeneity of Alpha 1-Acid Glycoprotein: Variation during the Menstrual Cycle in Healthy Women, and Profile in Women Receiving Estrogen-Progestogen Treatment," Clinical Chimica Acta, Vol. 187, No. 3, 1990, pp. 235241. doi:10.1016/0009-8981(90)90108-5

[32] U. K. Walle, T. C. Fagan, M. J. Topmiller, et al., "The Influence of Gender and Sex Steroid Hormones on the Plasma Binding of Propranolol Enantiomers," British Journal of Clinical Pharmacology, Vol. 37, No. 1, 1994, pp. 21-25.

[33] M. C. Carrasco-Portugal and F. J. Flores-Murrieta, "Gender Differences in the Oral Pharmacokinetics of Fluconazole," Clinical Drug Investigation, Vol. 27, No. 12, 2007 , pp. 851-856. doi:10.2165/00044011-200727120-00007

[34] A. J. Carcas, P. Guerra, J. Frias, et al., "Gender Differences in the Disposition of Metronidazole," International Journal of Clinical Pharmacology and Therapeutics, Vol. 39, No. 5, 2001, pp. 213-218.

[35] S. Zhou, S. Y. Chan, B. C. Goh, et al., "Mechanism-Based Inhibition of Cytochrome P450 3A4 by Therapeutic Drugs," Clinical Pharmacokinetics, Vol. 44, No. 3, 2005, pp. 279-304. doi:10.2165/00003088-200544030-00005

[36] E. Galli and L. Feijoo, "Citocromo P-450 y su Importancia Clínica Revisión Actualizada," Revista de NeuroPsiquiatria, Vol. 65, 2002, pp. 187-201.

[37] M. Fabrazzo, G. Esposito, R. Fusco, et al., "Effect of
Treatment Duration on Plasma Levels of Clozapine and N-Desmethylclozapine in Men and Women," Psychopharmacology, Vol. 124, No. 1-2, 1996, pp. 197-200. doi:10.1007/BF02245621

[38] M. Jerling, Y. Merle, F. Mentre, et al., "Population Pharmacokinetics of Clozapine Evaluated with a Non-Parametric Maximum Likelihood Method," British Journal of Clinical Pharmacology, Vol. 44, 1997, pp. 447-453. doi:10.1046/j.1365-2125.1997.t01-1-00606.x

[39] E. Skogh, M. Reis, M. L. Dahl, et al., "Therapeutic Drug Monitoring Data on Olanzapine and Its N-Demethyl Metabolite in the Naturalistic Clinical Setting," Therapeutic Drug Monitoring, Vol. 24, No. 4, 2002, pp. 518-526. doi:10.1097/00007691-200208000-00010

[40] M. W. Jann, T. L. ZumBrunnen, S. N. Tenjarla, et al., "Relative Bioavailability of Ondansetron 8-Mg Oral Tablets Versus Two Extemporaneous 16-Mg Suppositories: Formulation and Gender Differences," Pharmacotherapy, Vol. 18, No. 2, 1998, pp. 288-294.

[41] K. Kim, J. A. Johnson and H. Derendorf, "Differences in Drug Pharmacokinetics between East Asian and Caucasians and the Role of Genetic Polymorphisms," Journal of Clinical Pharmacology, Vol. 44, 2004, pp. 1083-1105. doi:10.1177/0091270004268128

[42] C. Martinez, G. Blanco, E. Garcia-Martin, et al., "Farmacogenómica Clínica de cyp2c8 y cyp2c9: Conceptos Generales y Aplicación al Uso de AINE," Farmacia Hospitalaria, Vol. 30, No. 4, 2006, pp. 240-248. doi:10.1016/S1130-6343(06)73982-4

[43] M. C. Meyer, A. B. Straughn, R. M. Mhatre, et al., "Variability in the Bioavailability of Phenytoin Capsules in Males and Females," Pharmaceutical Research, Vol. 18, No. 3, 2001, pp. 394-397. doi:10.1023/A:1011075502215

[44] Z. Desta, X. Zhao, J. G. Shin, et al., "Clinical Significance of the Cytochrome P450 2C19 Genetic Polymorphism," Clinical Pharmacokinetics, Vol. 41, No. 12, 2002, pp. 913-958. doi:10.2165/00003088-200241120-00002

[45] G. D. Anderson, "Sex and Racial Differences in Pharmacological Response: Where is the Evidence? pharmacogenetics, Pharmacokinetics, and Pharmacodynamics," Journal of Women Health, Vol. 14, No. 1, 2005, pp. 19-29.

[46] L. Bertilsson, "Geographical/Interracial Differences in Polymorphic Drug Oxidation. Current State of Knowledge of Cytochromes P450 (CYP) 2D6 and 2C19," Clinical Pharmacokinetics, Vol. 29, No. 3, 1995, pp. 192209. doi:10.2165/00003088-199529030-00005

[47] J. S. McCune, C. Lindley, J. L. Decker, et al., "Lack of gender differences and large intrasubject variability in cytochrome P450 activity measured by phenotyping with dextromethorphan," Journal of Clinical Pharmacology Vol. 41, 2001, pp. 723-731. doi:10.1177/00912700122010627

[48] A. B. Luzier, A. Killian, J. H. Wilton, et al., "Gender-related effects on metoprolol pharmacokinetics and pharmacodynamics in healthy volunteers," Clinical 
Pharmacology and Therapeutics Vol. 66, 1999, pp. 594601.

[49] S. R. Johansson and A. Hjalmarson, "Age and Sex Differences in Cardiovascular Reactivity to Adrenergic Agonists, Mental Stress and Isometric Exercise in Normal Subjects," Scandinavian Journal of Clinical Laboratoy Investigation, Vol. 48, No. 2, 1988, pp. 183-199. doi:10.1038/clpt.1994.176

[50] M. White and H. Leenen, "Aging and Cardiovascular Responsiveness to B-Agonist in Humans. Role of Changes in Beta-Receptor Responses Versus Baroreflex Activity," Clinical Pharmacology and Therapeutics, Vol. 56, 1994, pp. 543-553.

[51] M. Spatzenegger and W. Jaeger, "Clinical Importance of Hepatic Cytochrome P450 in Drug Metabolism," Drug Metabolism Revisited, Vol. 27, 1995, pp. 397-417. doi:10.3109/03602539508998329

[52] D. Lucas, C. Menez, C. Girre, et al., "Cytochrome P450 2E1 Genotype and Chlorzoxazone Metabolism in Healthy and Alcoholic Caucasian Subjects," Pharmacogenetics, Vol. 5, No. 5, 1995, pp. 298-304. doi:10.1097/00008571-199510000-00005

[53] C. Hoyo-Vadillo, G. Castañeda-Hernández, J. E. Herrera, et al., "Pharmacokinetics of Oral Nifedipine: Relevance of the Distribution Phase," Journal of Clinical Pharmacology, Vol. 29, No. 3, 1989, pp. 251-256.

[54] M. C. Carrasco-Portugal, M. Lujan and F. J. Flores- Murrieta, "Evaluation of Gender in the Oral Pharmacokinetics of Clindamycin in Humans," Biopharmaceutics and Drug Disposition, Vol. 29, No. 7, 2008, pp. 427-430. doi:10.1002/bdd. 624

[55] Y. Lin, G. D. Anderson, E. Kantor, et al., "Differences in the Urinary Excretion of 6-Betahydroxycortisol/Cortisol between Asian and Caucasian Women," Journal of Clinical Pharmacology, Vol. 39, No. 6, 1999, pp. 578582. doi: $10.1177 / 00912709922008182$
[56] B. Meibohm, I. Beierle and H. Derendorf, "How Important are Gender Differences in Pharmacokinetics," Clinical Pharmacokinetics, Vol. 41, No. 5, 2002, pp. 329-342. doi:10.2165/00003088-200241050-00002

[57] G. D. Anderson, "Sex Differences in Drug Metabolism. Cytochrome P-450 and Uridine Diphosphate Glucuronosyltransferase," Journal of Gender Specific Medicine, Vol. 5, 2002, pp. 25-33.

[58] J. L. Gross, R. Friedman, N. J. Azevedo, et al., "Effect of Age and Sex on Glomerular Filtration Rate Measured by 51Cr-EDTA," Brazilian Journal of Medical and Biological Research, Vol. 25, No. 2, 1992, pp. 129-134.

[59] J. H. Schlattjan, F. Biggemann and J. Greven, "Gender Differences in Renal Tubular Taurocholate Transport," Naunyn Schmiedebergs Archives of Pharmacology, Vol. 371, No. 6, 2005, pp. 449-456. doi:10.1007/s00210-005-1081-3

[60] Y. Kato, K. Kuge, H. Kusuhara, et al., "Gender Difference in the Urinary Excretion of Organic Anions in Rats," Journal of Pharmacology and Experimental Therapeutics, Vol. 302, No. 2, 2002, pp. 483-489. doi:10.1124/jpet.102.033878

[61] N. Kudo, M. Katakura, Y. Sato, et al., "Sex HormoneRegulated Renal Transport of Perfluorooctanoic Acid," Chemical Biological Interactions, Vol. 139, No. 3, 2002, pp. 301-316. doi:10.1016/S0009-2797(02)00006-6

[62] J. A. Cerrutti, N. B. Quaglia, A. Brandoni, et al., "Effects of Gender on the Pharmacokinetics of Drugs Secreted by the Renal Organic Anions Transport System in the Rat," Pharmacological Research, Vol. 45, 2002, pp. 107-112. doi:10.1006/phrs.2001.0912

[63] J. L. Rinn, J. S. Rosowsky, I. J. Laurenzi, et al., "Major Molecular Differences between Mammalian Sexes are Involved in Drug Metabolism and Renal Function," Developmental Cell, Vol. 6, No. 6, 2004, pp. 791-800. doi:10.1016/j.devcel.2004.05.005 